\title{
Intermittent Hypoxia Promotes Hippocampal Neurogenesis and Produces Antidepressant-Like Effects in Adult Rats
}

\author{
Xin-Hong Zhu, ${ }^{1 \star}$ Hua-Cheng Yan, ${ }^{1 \star}$ Jie Zhang, ${ }^{1}$ Hong-Da Qu, ${ }^{1}$ Xing-Sheng Qiu, ${ }^{2}$ Liang Chen, ${ }^{1}$ Shu-Ji Li, ${ }^{1}$ Xiong Cao, ${ }^{1}$ \\ Jonathan C. Bean, ${ }^{3}$ Long-Hua Chen, ${ }^{2}$ Xi-He Qin, ${ }^{1}$ Ji-Hong Liu, ${ }^{1}$ Xiao-Chun Bai, ${ }^{1}$ Lin Mei, ${ }^{1,3}$ and Tian-Ming Gao ${ }^{1}$ \\ ${ }^{1}$ Department of Anatomy and Neurobiology, Southern Medical University, Guangzhou 510515, China, ${ }^{2}$ Department of Radiation Oncology, Nanfang \\ Hospital, Southern Medical University, Guangzhou 510515, China, and 3Program of Developmental Neurobiology, Institute of Molecular Medicine and \\ Genetics, Department of Neurology, Medical College of Georgia, Augusta, Georgia 30912
}

Increasing evidence indicates that stimulating hippocampal neurogenesis could provide novel avenues for the treatment of depression, and recent studies have shown that in vitro neurogenesis is enhanced by hypoxia. The aim of this study was to investigate the potential regulatory capacity of an intermittent hypobaric hypoxia $(\mathrm{IH})$ regimen on hippocampal neurogenesis and its possible antidepressant-like effect. Here, we show that IH promotes the proliferation of endogenous neuroprogenitors leading to more newborn neurons in hippocampus in adult rats. Importantly, IH produces antidepressant-like effects in multiple animal models screening for antidepressant activity, including the forced swimming test, chronic mild stress paradigm, and novelty-suppressed feeding test. Hippocampal x-ray irradiation blocked both the neurogenic and behavioral effects of $\mathrm{IH}$, indicating that $\mathrm{IH}$ likely produces antidepressant-like effects via promoting neurogenesis in adult hippocampus. Furthermore, IH stably enhanced the expression of BDNF in hippocampus; both the antidepressantlike effect and the enhancement of cell proliferation induced by IH were totally blocked by pharmacological and biological inhibition of BDNF-TrkB (tyrosine receptor kinase B) signaling, suggesting that the neurogenic and antidepressant-like effects of IH may involve BDNF signaling. These observations might contribute to both a better understanding of physiological responses to IH and to developing IH as a novel therapeutic approach for depression.

\section{Introduction}

Depression is a common mental disorder in the general population. All currently available antidepressants (ADs) including tricyclic ADs, monoamine oxidase inhibitors, and serotonin and/or norepinephrine selective reuptake inhibitors have the same core mechanisms of action in promoting monoamine neurotransmitters (Nemeroff and Owens, 2002). Unfortunately for patients and clinicians, the mood improvement starts only after 3-6 weeks of AD treatment. Similarly, in animal behavioral models of depression, a period of 2-3 weeks of continuous administration is required to obtain an $\mathrm{AD}$-like effect. More efficacious $\mathrm{AD}$ therapies are in urgent demand.

Several lines of evidence suggest that adult hippocampal neurogenesis is important in depression, thoroughly changing the strategies we use for searching novel interventions of depression (Sahay and Hen, 2007). Stress has been shown to suppress adult hippocampal neurogenesis in different species (Gould et al.,

Received Dec. 28, 2009; revised July 10, 2010; accepted July 12, 2010.

This work was supported in part by grants from the Natural Science Foundation of China (30672660 to X.-H.Z., U0632007 to T.-M.G.), Key Project of Guangzhou City (2007Z1-E0081 to X.-H.Z, T.-M.G.), National Basic Research Program of China (2006CB504100), PCSIRT (IRT0731), Key Project of Guangdong Province (067007 and 9351051501000003), and Cheung Kong Scholars Programme (T.-M.G.).

${ }^{*}$ X.-H.Z. and H.-C.Y. contributed equally to this work.

Correspondence should be addressed to either Dr. Xin-Hong Zhu or Dr. Tian-Ming Gao, Department of Anatomy and Neurobiology, Southern Medical University, Guangzhou 510515, China. E-mail: zhuxh@fimmu.com or tgao@fimmu.com.

D0I:10.1523/JNEUROSCI.6414-09.2010

Copyright $\odot 2010$ the authors $\quad 0270-6474 / 10 / 3012653-11 \$ 15.00 / 0$
1997; 1998). Conversely, chronic treatment with different classes of ADs increases neurogenesis and reverses stress-induced inhibition of neurogenesis in adult hippocampus (Malberg et al., 2000; Czeh et al., 2001; Malberg and Duman, 2003; Alonso et al., 2004). Moreover, the time course of maturation of newly generated neurons in the dentate gyrus (DG) is generally consistent with the delayed onset of actions of ADs (Ngwenya et al., 2006). The most compelling evidence linking adult hippocampal neurogenesis with $\mathrm{ADs}$ comes from the elegant studies demonstrating that suppression of hippocampal neurogenesis by localized $\mathrm{x}$-ray irradiation inhibits behavioral actions of different ADs in rodent behavioral screens for AD activity (Santarelli et al., 2003; Jiang et al., 2005; Airan et al., 2007). In addition to ADs, other interventions that confer $\mathrm{AD}$-like behavioral effects, including electroconvulsive seizure, enriched environment, and exercise, also stimulate adult hippocampal neurogenesis (Kempermann et al., 1997; van Praag et al., 1999; Madsen et al., 2000; Hattori et al., 2007; Hunsberger et al., 2007). Together, these observations strongly suggest a link between increased hippocampal neureogenesis and AD activity (Yan et al., 2010).

Repeated episodes of hypobaric hypoxia interspersed with normoxic periods [intermittent hypobaric hypoxia (IH)] have long been used for training pilots, mountaineers, and athletes, and even applied for treatment and prevention of human diseases such as hypertension (Serebrovskaya et al., 2008), ischemic coronary artery diseases (Zhu et al., 2006), Parkinson's disease (Lin et al., 2002), and acute myeloid leukemia (Liu et al., 2006). Recently, it has been shown that hypoxia promoted neurogenesis in 
vitro (Shingo et al., 2001; Jin et al., 2002) and enhanced the proliferation of neuroprogenitor cells (NPCs) in vivo (Zhu et al., 2005). In this context, we investigated the in vivo effects of $\mathrm{IH}$ on hippocampal neurogenesis and its potential AD effects. We found that $\mathrm{IH}$ increased the proliferation of endogenous NPCs leading to more newborn neurons in the DG in adult rats. To investigate the $\mathrm{AD}$-like effects of $\mathrm{IH}$, we used three animal models screening for AD activity, including the forced swimming test (FST), the chronic mild stress (CMS) paradigm, and the novelty suppressed feeding (NSF) test. Furthermore, the potential mechanisms underlying the neurogenic and $\mathrm{AD}$-like effects induced by IH were investigated.

\section{Materials and Methods}

Animals. Studies were conducted on 3-month-old male Sprague Dawley rats (weighing 180-220 g) obtained from the Southern Medical University Animal Center (Guangzhou, China). Three or four rats were housed per cage each fitted with stainless-steel wire-mesh bottoms. The house conditions were maintained at $24 \pm 1{ }^{\circ} \mathrm{C}$ room temperature (RT) and were under a $12 \mathrm{~h}$ light/dark daily cycle (lights on from 6:00 A.M. to 6:00 P.M.), excluding for CMS experiment (see below). Food and water were available ad libitum. All experiments were conducted during the light cycle in accordance with the Chinese Council on Animal Care Guidelines. The procedures were approved by the local animal care committee. Behavioral tests were performed, single blindly, between 1:30 P.M. and 4:30 P.M., and the testing area was dimly lit to limit stress and anxiety.

Materials. Bromodeoxyuridine (BrdU), cobalt chloride $\left(\mathrm{CoCl}_{2}\right)$, fluoxetine, imipramine, and haloperidol (Sigma-Aldrich) were dissolved in nonpyrogenic $0.9 \% \mathrm{NaCl}$ and filtered at $0.2 \mu \mathrm{m}$. All these compounds were injected intraperitoneally. K252a (Calbiochem) was dissolved in sterilized artificial CSF (ACSF)/50\% DMSO (Sigma). Chicken antiBDNF neutralizing antibody and chicken IgY control Ig (Promega) were each diluted in sterilized ACSF to a concentration of $20 \mu \mathrm{g} / \mathrm{ml}$.

IH training protocol. Rats were housed in a thick-walled high-pressureresistant glass animal chamber commercially designed $(76 \times 50 \times 50$ $\mathrm{cm}^{3}$ ), fitted with a brass lid and three brass outlets connected to the other components of the unit via vacuum tubes. Briefly, the first outlet was connected to a high-pressure vacuum pump with a pressure gauge through a copper tube. The second outlet was connected to a manometer that indicated the barometric pressure, whereas the third outlet was fitted to an adjustable knob to regulate the entry of air, and hence the developed pressure in the chamber. During the simulation, pressure was gradually decreased until a particular pressure, equivalent to that at an altitude of 3000 or $5000 \mathrm{~m}$ (i.e., $P_{\mathrm{B}}=404 \mathrm{mmHg} ; P_{\mathrm{O} 2}=84 \mathrm{mmHg}$, equivalent to an altitude of $5000 \mathrm{~m}$ ) was reached. After exposing the animals to the decreased pressure for $4 \mathrm{~h}$, the pressure was gradually increased to reach the normal level in $15 \mathrm{~min}$. The schedule was followed at the same period once daily for 14 consecutive days, and the chamber was cleaned every day. For the normoxic control, animals were kept in the chamber circulated with room air for $4 \mathrm{~h}$ during the corresponding period.

Tissue processing. Rats were deeply anesthetized with $10 \%$ chloral hydrate $(35 \mathrm{mg} / 100 \mathrm{~g}$ body weight, i.p.) and were killed by transcardial perfusion with $100 \mathrm{ml}$ of heparinized $0.9 \%$ saline followed by $200 \mathrm{ml}$ of ice-cold 4\% paraformaldehyde in PBS $(0.1 \mathrm{M}), \mathrm{pH}$ 7.2-7.4. Brains were postfixed at $4^{\circ} \mathrm{C}$ for $4-6 \mathrm{~h}$ in the same fixative, transferred to PBS containing $30 \%$ sucrose $\left(4^{\circ} \mathrm{C}\right.$ for $\left.48 \mathrm{~h}\right)$, and then frozen. Adjacent sections (corresponding to the following coronal coordinates: interaural 4.48$5.86 \mathrm{~mm}$, from bregma -3.14 to bregma -4.52 ) were cut on a cryotome (Leica CM 1850) at $10 \mu \mathrm{m}$ [for neuronal nuclear antigen (NeuN) and terminal deoxynucleotidyl transferase (TdT)-mediated biotin-dUTP nick-end labeling (TUNEL) staining] or $30 \mu \mathrm{m}$ [for BrdU, doublecortin (DCX), and double-immunofluorescence staining] and stored at $-80^{\circ} \mathrm{C}$ until used.

Immunostaining. Immunostaining was performed according to a procedure routinely performed in our laboratory (Yan et al., 2010; Zhu et al., 2010). The primary antibodies used in the present study are as follows: mouse monoclonal anti-BrdU ( $2 \mu \mathrm{g} / \mathrm{ml}$; Roche); sheep polyclonal anti$\operatorname{BrdU}(25 \mu \mathrm{g} / \mathrm{ml}$; BioDesign); goat polyclonal anti-DCX (1:200; Santa
Cruz Biotechnology); mouse monoclonal anti-NeuN (1:200; Millipore Bioscience Research Reagents); rabbit polyclonal anti-S-100 $\beta$ (1:1000; Swant). The second antibodies used are FITC-conjugated goat antimouse IgG, FITC-conjugated goat anti-rabbit IgG, and rhodamineconjugated rat-absorbed donkey anti-sheep $\operatorname{IgG}$ (1:200; Jackson ImmunoResearch). For BrdU ${ }^{+}$cells quantification, we used a modified protocol that has been reported to successfully quantitate BrdU labeling (Gould et al., 1997; Jin et al., 2002). Briefly, for each experiment, the slides were coded before quantitative analysis, and the code was not broken until the analysis was complete. $\mathrm{BrdU}^{+}$cells were counted at $400 \times$ magnification under the microscope by an investigator blinded to treatment history. For each brain, at least six sections were selected for analysis from the middle to caudal DG. For each selected section, the number of $\mathrm{BrdU}^{+}$cells was quantified in the DG [the granule cell layer (GCL) and hilus; cells that were located more than two cells away from the subgranular zoon (SGZ) were combined]. The cross-sectional area of the DG was determined by use of an IPP Interactive Digitizing Analysis System (Olympus).

For double labeling, slices were analyzed under a confocal microscope. At least $50 \mathrm{BrdU}^{+}$cells per animal were analyzed using Z-plane sectioning ( $1 \mu \mathrm{m}$ steps) to confirm the colocalization of the markers for both BrdU and NeuN.

Quantification of neurons. The density of $\mathrm{NeuN}^{+}$cells in CA1 region and granular cell layer was calculated (per $1 \mathrm{~mm}$ liner length) at $400 \times$ magnification under light microscopy (Olympus BX51 system) as per our previous description (Zhu et al., 2010).

TUNEL analysis. Apoptotic cells was analyzed using TUNEL detection kits (S7100; Intergen) as previously described (Zhu et al., 2010). Briefly, $10 \mu \mathrm{m}$ coronal sections were microwaved for $5 \mathrm{~min}$ and brought to RT and rehydrated in PBS. Endogenous peroxidase activity was quenched for $10 \mathrm{~min}$ in $3 \% \mathrm{H}_{2} \mathrm{O}_{2}$ in methanol. Sections were washed two times for $5 \mathrm{~min}$ in PBS, and equilibration water was applied for $30 \mathrm{~min}$ under RT, followed by applying a reaction mixture of $55 \mu \mathrm{l} / 5 \mathrm{~cm}^{2}$ of workingstrength TdT enzyme. Sections were then incubated at $37^{\circ} \mathrm{C}$ for $60 \mathrm{~min}$. After washing in stop/wash buffer for $15 \mathrm{~s}$, slices were incubated in antidigoxigenin peroxidase conjugate for $30 \mathrm{~min}$ at RT and washed in PBS four times for $2 \mathrm{~min}$ each. The sections were colorized with a 3,3'diaminobenzidine kit (Boster) and then washed in PBS to end the reaction. After washing with water, sections were allowed to dry overnight, counterstained with $0.5 \%$ (weight/volume) methyl green, coverslipped, and detected with the Olympus BX51 system microscope. Only yellowstaining cells were counted as apoptotic phenotype. Sections obtained from brains that received an x-ray dose of $10 \mathrm{~Gy}$ were used as a positive control.

FST. The rats were handled daily for 3-5 d before testing. The modified FST for rat was conducted essentially as described by Detke et al. (1995). Briefly, rats were placed individually in glass cylinders $(\Phi 21 \times 46 \mathrm{~cm}$; Jiliang) that were filled with water $\left(23 \pm 1^{\circ} \mathrm{C}\right)$ to a $30 \mathrm{~cm}$ depth. The rats were removed $15 \mathrm{~min}$ later, dried, and placed in their home cage. Twenty-four hours after their first exposure, the animals were again placed in the chamber for $5 \mathrm{~min}$ and behaviors were monitored from side by video camera for subsequent analysis. The rater of the behavioral patterns was blinded with respect to the experimental parameters being scored. A time-sampling technique was used whereby the predominant behavior in each $5 \mathrm{~s}$ period of the $300 \mathrm{~s}$ test was recorded. Climbing behavior consisted of upward-directed movements of the forepaws along the side of the swim chamber. Swimming behavior was defined as movement (usually horizontal) throughout the swim chamber, which also included crossing into another quadrant. Immobility was assigned when no additional activity was observed other than that required to keep the rat's head above the water. Following documented protocols, drugs were injected (i.p.) three times, 1, 5, and $23.5 \mathrm{~h}$ before the test session at an injection volume of $2 \mathrm{ml} / \mathrm{kg}$.

Open field test. The open-field apparatus was a rectangular chamber $(60 \times 60 \times 40 \mathrm{~cm})$ made of gray polyvinyl chloride. A video camera, a loudspeaker providing masking noise, and a $25 \mathrm{~W}$ red light bulb placed $200 \mathrm{~cm}$ above the maze (illumination density at the center of the maze, 0.3 lux) were positioned above its center. The digitized image of the path taken by each animal was stored and analyzed post hoc. After each trial, 
A

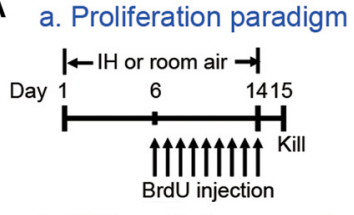

b. Differentiation paradigm

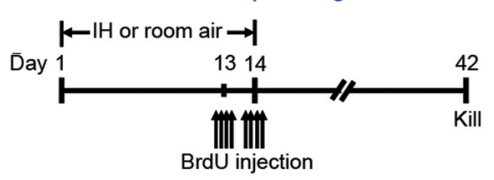

C

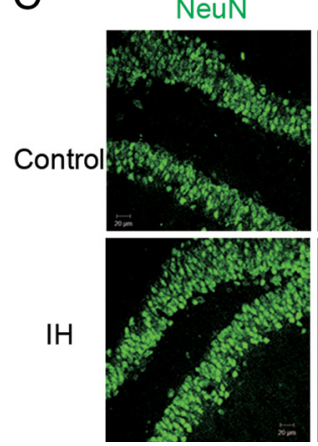

BrdU
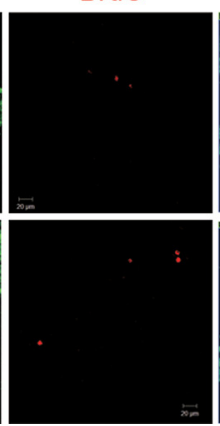

B

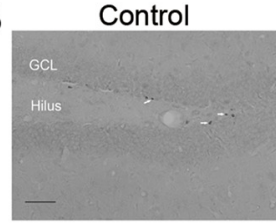

IH 5000m
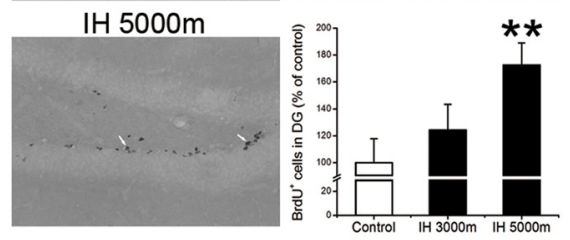

NeuN/BrdU

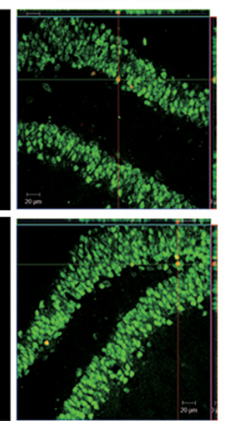

D

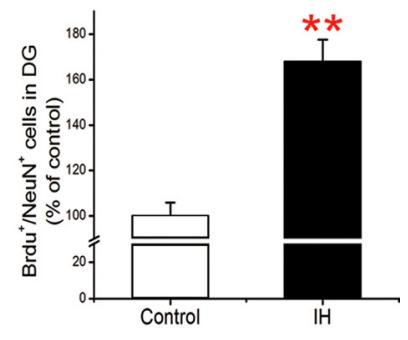

Figure 1. IH enhances neurogenesis in adult hippocampus. $A$, Experimental paradigm. $\boldsymbol{a}$, Proliferation paradigm. Animals were subjected to IH (mimicking 3000 or $5000 \mathrm{~m}$ in altitude) for $14 \mathrm{~d}$. BrdU ( $50 \mathrm{mg} / \mathrm{kg}$, i.p.) was daily injected for $9 \mathrm{~d}$ and rats were killed $24 \mathrm{~h}$ after the last BrdU injection. $\boldsymbol{b}$, Differentiation paradigm. Rats were subjected to $\mathrm{IH}$ mimicking $5000 \mathrm{~m}$ in altitude and BrdU was injected at the last $2 \mathrm{~d}$ during IH. Then, animals were killed $28 \mathrm{~d}$ after IH. B. The majority of the BrdU ${ }^{+}$cells (arrows) are clustered or aggregated in the $\mathrm{SGZ}$, the region between the $\mathrm{GCL}$ and hilus, and the number of $\mathrm{BrdU}^{+}$cells was increased by $\mathrm{IH}$ mimicking $5000 \mathrm{~m}$ in altitude. ${ }^{* *} p<0.01$ versus control by LSD post hoc analysis after one-way ANOVA. C, Representative confocal microscopic images. Z-axis images were made to analyze double-labeled newborn neurons. The majority of $\mathrm{BrdU}^{+}{ }^{+}$cells (red) were also labeled with NeuN (green) and located within the GCL. D, The number of $\mathrm{BrdU}^{+} / \mathrm{NeuN}^{+}$cells was increased in IH-treated hippocampus. ${ }^{* *} p<0.01$ versus control by an independent-sample $t$ test. The results are expressed as means $\pm S E M ; n=6$ in each group. Scale bars: $\boldsymbol{B}, 100 \mu \mathrm{m} ; \boldsymbol{C}, 20 \mu \mathrm{m}$.

the apparatus was swept out with water containing $0.1 \%$ acetic acid. The floor of the open-field was divided into 36 rectangles $(10 \times 10 \mathrm{~cm})$. Animals were gently placed on the center square, and left to explore the arena for $5 \mathrm{~min}$. The locomotion activity was registered as the distance in squares an animal moved.

CMS. Male albino Wistar rats (3 months old, weighing 220-250 g, obtained from the Southern Medical University Animals Center) were singly caged and pretested with coat score assessment. The total coat score resulted from the sum of the score of seven different body parts: head, neck, dorsal coat, ventral coat, tail, forepaws, and hindpaws. For each of the seven body areas, a score of 1 was given for a well-groomed coat and 0 for an unkempt coat. This index has been pharmacologically validated (Griebel et al., 2002; Alonso et al., 2004). In the present study, the state of each rat's fur was assessed and assigned a score at the beginning of CMS (before CMS), at the end of the third week (before treatment), and $7 \mathrm{~d}$ after treatment (after treatment). One day after pretest, rats were subjected to CMS for 5 weeks in total. CMS was performed according to a slightly modified version of protocol published previously (Willner et al., 1992). The CMS protocol consists of the sequential application of a variety of mild stressors, including restraint, forced swim in ice-cold water ( $5 \mathrm{~min}$ ), food and water deprivation ( $24 \mathrm{~h}$ ), cage tilting $\left(45^{\circ}\right)$, reversal of the light/dark cycle, strobe light, and pairing with another stressed animal, in a schedule that lasts for 3 weeks and is repeated thereafter. For treatment, IH, fluoxetine $(10 \mathrm{mg} / \mathrm{kg}$, i.p.) or saline (i.p.) was given at the beginning of the fourth week and continued to $14 \mathrm{~d}$ (see Fig. $3 A$ ). The NSF test was conducted $7 \mathrm{~d}$ after CMS. For newborn cell labeling, $\mathrm{BrdU}(50 \mathrm{mg} / \mathrm{kg}$, i.p.) was injected at 4:00 P.M. once daily for $7 \mathrm{~d}$ (during the fifth week). Animals were killed $2 \mathrm{~h}$ after the behavioral test and brain slice were prepared for BrdU staining.
NSF test. Twenty-four hours after food deprivation, rats were placed in a plastic box $(50 \times 50 \times 20 \mathrm{~cm})$ in which the floor was covered with $\sim 2$-cm-thick wooden bedding, where they were subjected to the NSF test for 5 $\mathrm{min}$. At the beginning of the each test, a single pellet of food was placed on a white paper platform positioned at the center of the box. When a rat was placed in a corner of the maze, a stopwatch was immediately started. The scoring for measure of interest did not begin until the rat reached for the food with its forepaws and began eating. Immediately after the test, the rat was transferred to its home cage and the amount of food consumed in the next $5 \mathrm{~min}$ was measured (home-cage food intake).

Irradiation. Irradiation was performed according to a modified version of a procedure reported previously (Santarelli et al. 2003). Briefly, rats were anesthetized and placed in a stereotaxic frame and exposed to cranial irradiation using a Siemens Stabilopan x-ray system operated at $300 \mathrm{kVp}$ and $20 \mathrm{~mA}$. Animals were protected with a lead shield that covered the entire body, with the exception of a $3.5 \times$ $14 \mathrm{~mm}$ treatment field above the hippocampus. The corrected dose rate was $\sim 1.8$ Gy per minute at a source-to-skin distance of $30 \mathrm{~cm}$. The procedure lasted $2 \mathrm{~min}$ and $51 \mathrm{~s}$, delivering a total of $5 \mathrm{~Gy}$. Three $5 \mathrm{~Gy}$ doses were delivered on days 1,4 , and 8 during $\mathrm{IH}$, respectively. To assess the effects of this procedure on neurogenesis, rats injected with $\mathrm{BrdU}(4 \times 75 \mathrm{mg} / \mathrm{kg}$ at $2 \mathrm{~h}$ intervals, i.p.) on the last $2 \mathrm{~d}$ (days 13 and 14) during IH. Rats were killed $2 \mathrm{~h}$ after the behavioral tests, and brain slices were prepared for BrdU staining.

Western blotting. Hippocampal samples were prepared as described previously (Yan et al. 2010). Samples (total of $200 \mu \mathrm{g}$ of lysates) were subjected to electrophoresis in SDS-10\% polyacrylamide gels and transferred to polyvinylidene fluoride membranes by standard procedures. The membranes were blocked with $5 \%$ nonfat milk and incubated overnight at $4^{\circ} \mathrm{C}$ with the following antibodies: monoclonal anti-HIF-1 $\alpha$ (1:500; Millipore Bioscience Research Reagents), rabbit polyclonal anti-BDNF (1:500; Millipore Bioscience Research Reagents), rabbit polyclonal anti-erythropoietin (EPO; 1:200; Santa Cruz Biotechnology), and mouse monoclonal anti- $\beta$-actin ( $1: 1000$; Bostor). This was followed by incubation with secondary horseradish peroxidase-conjugated antibodies and enhanced chemiluminescence detection (GE Healthcare) and detected by the Quantitative Imaging System FluorChem SP (Alpha Innotech). To quantitate protein abundance, bands were analyzed with FluorChem SP software. Optical densities (ODs) were normalized to OD values for the corresponding $\beta$-actin on the same membranes.

Minipump infusion of K252a and anti-BDNF antibody. Intraventricular infusion of antibody has been used to investigate the protein's function (Shingo et al., 2001). In present study, we blocked BDNF-tyrosine receptor kinase $\mathrm{B}$ (TrkB) signaling using K252a and chicken anti-BDNF antibody, which has been shown to be neutralizing and specific for BDNF (Chen et al., 2005). Osmotic minipumps designed to deliver $0.5 \mu \mathrm{l} / \mathrm{h}$ for $14 \mathrm{~d}$ (Model 2002; Alzet) were filled with $50 \mu \mathrm{M} \mathrm{K252a} \mathrm{in} \mathrm{ACSF} / 50 \%$ DMSO, ACSF $/ 50 \%$ DMSO, $20 \mu \mathrm{g} / \mathrm{ml}$ chicken anti-BDNF neutralizing antibody, or $20 \mu \mathrm{g} / \mathrm{ml}$ chicken IgY in ACSF. Each osmotic minipump was attached to a brain infusion cannula that was placed in the right lateral cerebral ventricle ( -1.0 anteroposterior relative to bregma, $1.5 \mathrm{~mm}$ lateral to the midline, and $3.4 \mathrm{~mm}$ deep to the pial surface). The cannula was cemented in place, and the incision was sutured. Four days after surgery, animals exposed to $14 \mathrm{~d}$ IH mimicking $5000 \mathrm{~m}$ in altitude were given 
$\mathrm{BrdU}(4 \times 75 \mathrm{mg} / \mathrm{kg}$ at $2 \mathrm{~h}$ intervals, i.p. $)$ injections on the last $2 \mathrm{~d}$ (days 13 and 14) during $\mathrm{IH}$. Behaviors were tested $24 \mathrm{~h}$ after $\mathrm{IH}$, and $2 \mathrm{~h}$ later, rats were killed and brain slices were examined for BrdU staining (see Fig. 6Ab).

Statistical analysis. All data are expressed as mean \pm SEM. One-way ANOVA followed by the least significant difference (LSD) for post hoc comparisons or an independent-sample $t$ test was used for statistical analysis throughout the study unless specified otherwise. The significance level for all tests was set at $p<0.05$.

\section{Results}

IH enhances neurogenesis in adult hippocampus

The effect of $\mathrm{IH}$ on the proliferation of NPCs was first investigated. To this end, rats were subjected to $\mathrm{IH}$ for $14 \mathrm{~d}$, and proliferating cells were labeled by daily $\mathrm{BrdU}$ injection $(50 \mathrm{mg} / \mathrm{kg}$ body weight, i.p.) beginning on the sixth day of $\mathrm{IH}$ for 9 d (Fig. 1 $A a$ ). Rats were killed $24 \mathrm{~h}$ after $\mathrm{IH}$ paradigm ended. $\mathrm{BrdU}^{+}$cells were examined in the DG, a region where adult neurogenesis is implicated in $\mathrm{AD}$ (Sahay and Hen, 2007). As shown in Figure $1 B$, $\mathrm{BrdU}^{+}$cells appeared as in clusters or aggregates in the SGZ, as reported previously (Malberg et al., 2000; Yan et al., 2010). The number of $\mathrm{BrdU}^{+}$cells was increased by $\mathrm{IH}$ mimicking altitude of 3000 and $5000 \mathrm{~m}\left(F_{(2,15)}=16.628, p<\right.$ 0.001 ; post hoc analysis, $p<0.015000 \mathrm{~m}$ vs control), although the increase at $3000 \mathrm{~m}$ was not statistically significant ( $p=0.056$ vs control). In general agreement with a previous report (Zhu et al., 2005), which demonstrates that the number of $\mathrm{BrdU}^{+}$cells was increased in both the DG and subventricular zone by $14 \mathrm{~d} \mathrm{IH}$ mimicking 3000 and $5000 \mathrm{~m}$ in altitudes, these results suggest that $\mathrm{IH}$ promotes the proliferation of NPCs in adult hippocampus. Unless otherwise indicated, $\mathrm{IH}$ in this paper indicates $\mathrm{IH}$ mimicking $5000 \mathrm{~m}$ in altitude.

To determine whether the increased $\mathrm{BrdU}^{+}$cells induced by IH differentiate into new neurons, BrdU $(4 \times 75 \mathrm{mg} / \mathrm{kg}$ at $2 \mathrm{~h}$ intervals, i.p.) was injected at the last $2 \mathrm{~d}$ of $\mathrm{IH}$, and rats were killed $28 \mathrm{~d}$ after the last BrdU injection (Fig. $1 \mathrm{Ab}$ ). During this period, newly generated cells have been shown to differentiate to become neurons in the hippocampus (Kempermann et al., 2003). $\mathrm{NeuN}$ was used as a marker of mature neurons (Mullen et al., 1992). Unlike those examined right after BrdU injection, distributed as aggregates in the SGZ, BrdU ${ }^{+}$cells were dispersed in the GCL and appeared to be indistinguishable in size and morphology from neighboring granule neurons (Fig. $1 B, C$ ). Confocal microscopy, using Z-plane sections to confirm colocalization for each cell, revealed that the number of $\mathrm{NeuN}^{+} / \mathrm{BrdU}^{+}$(doublepositive) cells was significantly increased in IH-treated hippocampus $\left(t_{(1,10)}=8.414 ; p<0.01\right)($ Fig. $1 D)$, indicating that $\mathrm{IH}$ stimulates neurogenesis in adult hippocampus.

To further characterize the effect of IH on the fate of the newborn cells, rats injected with $\mathrm{BrdU}(4 \times 75 \mathrm{mg} / \mathrm{kg}$ body weight, i.p.; $2 \mathrm{~h}$ intervals) before IH were killed $28 \mathrm{~d}$ after the last $\mathrm{BrdU}$ injection. Brain slices were costained for BrdU and NeuN or S-100 $\beta$, a marker for matured astrocyte (Boyes et al., 1986).
The number of $\mathrm{BrdU}^{+}$cells in the DG was not different between control and IH-treated rats $\left(t_{(1,10)}=0.189 ; p=0.673 ; n=6\right)$, indicating that $\mathrm{IH}$ had no effect on the survival of newborn cells. Furthermore, the percentages of the $\mathrm{NeuN}^{+} / \mathrm{BrdU}^{+}(\mathrm{IH}, 76.2 \pm$ $4.1 \%$ vs control, $\left.73.7 \pm 2.5 \% ; t_{(1,10)}=0.005 ; p=0.942\right)$ and the $\mathrm{S}-100 \beta^{+} / \mathrm{BrdU}^{+}(\mathrm{IH}, 13.2 \pm 3.2 \%$ vs control, $13.5 \pm 1.2 \%$; $\left.t_{(1,10)}=0.15 ; p=0.781\right)$ in total $\mathrm{BrdU}^{+}$cells were not altered by $\mathrm{IH}$, suggesting that $\mathrm{IH}$ had no effect on the differentiation of newborn cells. Together, these results suggest that IH promotes the proliferation of NPCs, and thus enhances neurogenesis in adult hippocampus.

\section{IH produces $\mathrm{AD}$-like effect in the FST}

Having demonstrated the effect of IH on promoting hippocampal neurogenesis in adult brain, we next investigated for any $\mathrm{AD}$ effects related to $\mathrm{IH}$. It has been shown that $\mathrm{CoCl}_{2}$ can mimic hypoxia in animal models (Xi et al. 2004) and in cultured cells (Yuan et al., 2003); first, we investigated the neurogenic effect of $\mathrm{CoCl}_{2}$. To this end, rats were injected daily (intraperitoneally) with $\mathrm{CoCl}_{2}(2.5,7.5$, and $15 \mathrm{mg} / \mathrm{kg})$ or saline followed by BrdU injection (50 mg/kg, i.p.) for $6 \mathrm{~d}(n=6)$; animals were killed $24 \mathrm{~h}$ after treatments, and brain slices were prepared for BrdU immunostaining. The number of $\mathrm{BrdU}^{+}$cells in the DG was significantly increased $(45.7 \pm 17.6 \%)$ by $\mathrm{CoCl}_{2}$ at the dose of $7.5 \mathrm{mg} / \mathrm{kg}$ $\left(F_{(3,21)}=3.959 ; p<0.05\right.$ vs saline group $)$, but not at $15 \mathrm{mg} / \mathrm{kg}$ $(21.4 \pm 10.1 \%$ increase), probably because of toxicity at the high dose (Liu et al., 2006). Then, the AD effect of $\mathrm{CoCl}_{2}(7.5 \mathrm{mg} / \mathrm{kg}$ ) was examined in the FST, a widely used animal model for assessing pharmacological AD activity (Cryan et al., 2005). Fluoxetine $(20 \mathrm{mg} / \mathrm{kg}$, i.p.) and imipramine (30 mg/kg, i.p.), two well-know 
A
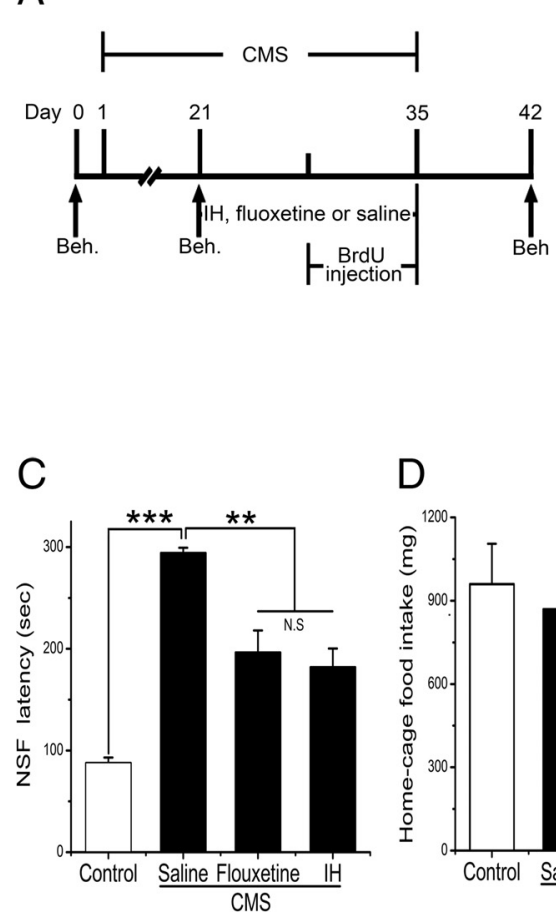
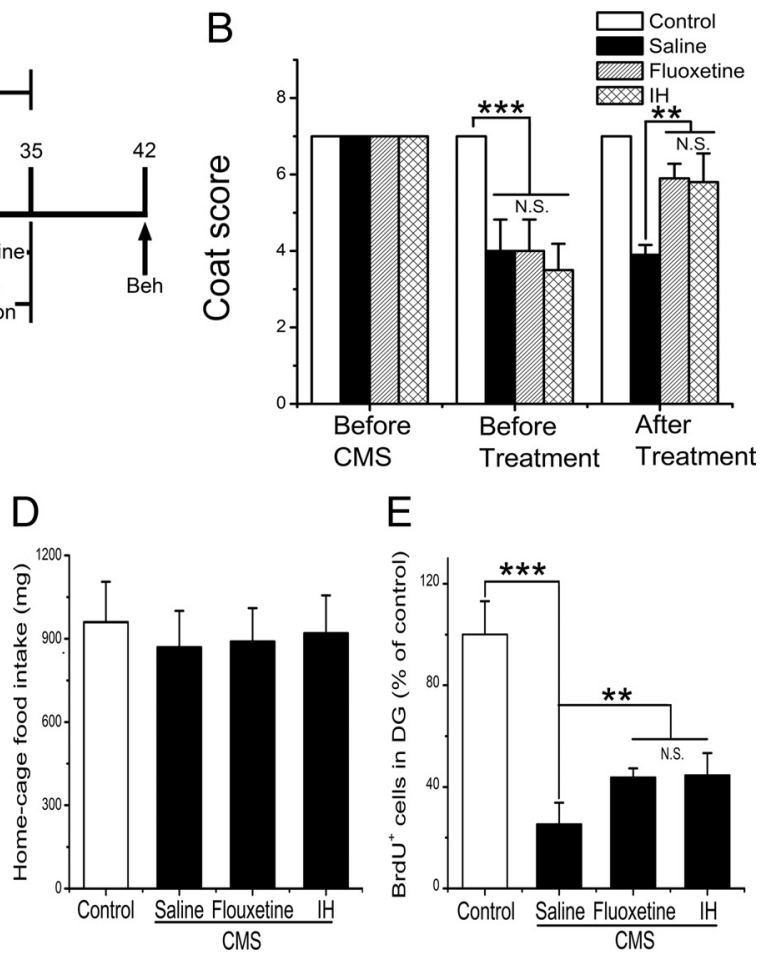

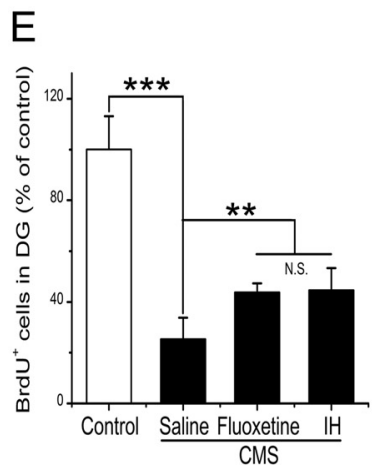

Figure 3. IH reverses depressive-like behavior in CMS paradigm. $\boldsymbol{A}$, Experimental design. Rats were exposed to CMS for 5 weeks. The state of each rat's fur was assessed at the beginning of CMS (before CMS), end of the third week (before treatment), and $7 \mathrm{~d}$ after treatment (after treatment; Beh.). The NSF test was performed $7 \mathrm{~d}$ after treatment. Treatments, including IH, fluoxetine (10 $\mathrm{mg} / \mathrm{kg}$ ) and saline, were administered from the beginning of the fourth week and lasted for 2 weeks. Animals were killed $2 \mathrm{~h}$ after the behavioral tests and brain slices were prepared for BrdU staining. Control rats were kept in the chamber circulated with room air in the corresponding period. $\boldsymbol{B}$, Animals showed coat state deterioration during CMS, an effect that could be reversed by both $\mathrm{IH}$ and fluoxetine. ${ }^{* *} p<0.01 ;{ }^{* * *} p<0.001$ versus saline group by repeated measures. $C$, Anxiety-like behaviors in the NSF test at $7 \mathrm{~d}$ after CMS. D, No difference was found in amount of food intake among four groups when rats were tested in their home cage after the NSF test. $\boldsymbol{E}$, CMS exposure significantly decreased the number of BrdU ${ }^{+}$cells in the DG, and this effect was fractionally reversed by fluoxetine and IH. ${ }^{* *} p<0.01$; ${ }^{* * *} p<0.001$ versus saline group by LSD post hoc analysis after one-way ANOVA. N.S., No significant difference. The results are expressed as means $\pm \mathrm{SEM}, n=7$ in each group.

ADs, were used as positive controls, and haloperidol $(1 \mathrm{mg} / \mathrm{kg}$, i.p.), a neuroleptic drug, was used as a negative control. Compared with saline group, both fluoxetine and imipramine exhibited the AD-like effects, evidenced by significantly decreasing immobility, whereas haloperidol had no effect (Fig. $2 \mathrm{~A}$ ), in agreement with previous reports (Cryan et al., 2005; Garcia et al., 2008). Interestingly, $\mathrm{CoCl}_{2}$ decreased immobility $\left(F_{(4,55)}=5.369\right.$; $p<0.01$; post hoc analysis, $p<0.05$ vs saline group) and increased climbing $\left(F_{(4,55)}=4.492 ; p<0.01\right.$; post hoc analysis, $p<0.05$ vs saline group), but had no effect on swimming $\left(F_{(4,55)}=3.82 ; p<\right.$ 0.01 ; post hoc analysis, $p=0.27$ vs saline group) (Fig. $2 A$ ), suggesting that $\mathrm{CoCl}_{2}$ could have $\mathrm{AD}$-like effect.

Next, we assessed IH's AD effect on the FST, conducted $24 \mathrm{~h}$ after IH. IH mimicking $3000 \mathrm{~m}$ in altitude had no effects on immobility $\left(t_{(1,22)}=0.449 ; p=0.658\right.$ vs control $)$, swimming $\left(t_{(1,22)}=0.434 ; p=0.669\right)$, or climbing $\left(t_{(1,22)}=0.281 ; p=\right.$ 0.781 ) in the FST. However, as shown in Figure $2 B$, IH (mimicking altitude of $5000 \mathrm{~m})$ decreased immobility $\left(t_{(1,22)}=2.567 ; p<\right.$ $0.05)$ and increased swimming $\left(t_{(1,22)}=2.072 ; p<0.05\right)$, but had no effect on climbing $\left(t_{(1,22)}=1.124 ; p=0.273\right)$ when compared with control. To exclude the possible effect of IH on spontaneous locomotor activity, which may contribute to the decreased immobility in the FST, animals were exposed to the open-field apparatus for $5 \mathrm{~min}$. There was clearly no difference in the number of squares animals crossed between two groups $\left(t_{(1,18)}=\right.$
$0.428 ; p=0.52$ ) (Fig. 2C), suggesting that $\mathrm{IH}$ might have $\mathrm{AD}$-like effect.

\section{IH reverses depression in CMS}

To further characterize the AD effect of $\mathrm{IH}$, we developed an animal model of depression following an established CMS paradigm (Willner et al. 1992). This paradigm results in a deterioration of the state of the coat that can be reversed by chronic AD treatments (Griebel et al., 2002; Santarelli et al., 2003). To this end, rats randomly divided into four groups (control, IH, fluoxetine, and saline groups; $n=7$ per group) were subjected to CMS, except the control rats, which were subjected to normoxic conditions. The state of each rat's fur was evaluated at the beginning of CMS (before CMS), at the end of the third week (before treatment), and $7 \mathrm{~d}$ after treatment (after treatment) (Fig. $3 A$ ). After 3 weeks of CMS, rats showed coat state deterioration (factor $F_{(3,24)}=$ $156.85 ; p<0.001$, repeated measures) (Fig. $3 B$ ). In contrast, the physical state of the animal's coat was improved by fluoxetine (group $F_{(3,24)}=18.583 ; p<0.001$; post hoc analysis, $p<0.01$ vs saline group, repeated measures) (Fig. $3 B$ ). This result is in agreement with previous reports (Griebel et al., 2002; Alonso et al., 2004). Strikingly, like fluoxetine, IH significantly improved the physical state of the fur ( $p<0.01$ vs saline group) (Fig. $3 B$ ), and there was no difference between fluoxetine and IH groups $(p=0.478)$. After the last fur score assay, we subjected the rats to the NSF test, which has been used to assess chronic AD efficacy in rats and in mice (Bodnoff et al., 1988; Santarelli et al., 2003). Exposure to CMS increased the latency to feed $\left(F_{(3,24)}=7.1 ; p<0.01 ;\right.$ post hoc analysis, $p<0.001$ control vs saline group), an effect that was partially reversed by fluoxetine ( $p<0.01$ vs saline group), in agreement with previous reports (Bessa et al., 2009). Most interestingly, IH decreased the CMSelevated latency ( $p<0.01$ vs saline group), and there was no difference between IH and fluoxetine groups ( $p=0.562)$ (Fig. $3 C$ ). Because ADs may alter appetite, we determined whether the reduced feeding latency by $\mathrm{IH}$ was attributable to a change in appetite. To this end, rats were immediately returned to their home-cages after the NSF test and scored for food consumption. There was clearly no difference in food consumption among four groups $\left(F_{(3,24)}=0.52 ; p=0.673\right)$ (Fig. $\left.3 D\right)$. Thus, it is unlikely that the reduction of the latency was attributable to a change in appetite. Also, there was no effect of $\mathrm{IH}$ on body weight of rats exhibiting depressive-like behavior (data not shown). These results together support the notion that IH could have an AD-like effect. Furthermore, CMS exposure significantly decreased the number of $\mathrm{BrdU}^{+}$cells $\left(F_{(3,24)}=6.1 ; p<0.001\right.$; post hoc analysis, $p<0.001$ control vs saline group), confirming that stressors suppress adult hippocampal neurogenesis (Gould et al., 1997; 1998). Remarkably, the decreased number of $\mathrm{BrdU}^{+}$cells in depressive rats was partially reversed by both fluoxetine and $\mathrm{IH}$ ( $p<0.01 \mathrm{IH}$ vs saline group) (Fig. $3 E$ ), suggesting that the AD- 
A

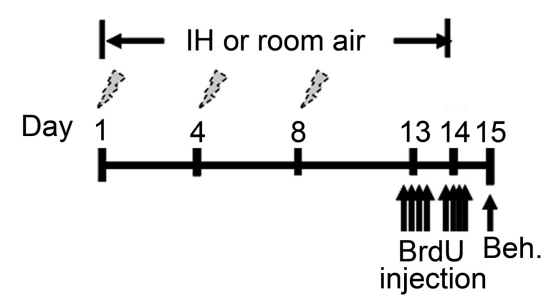

D

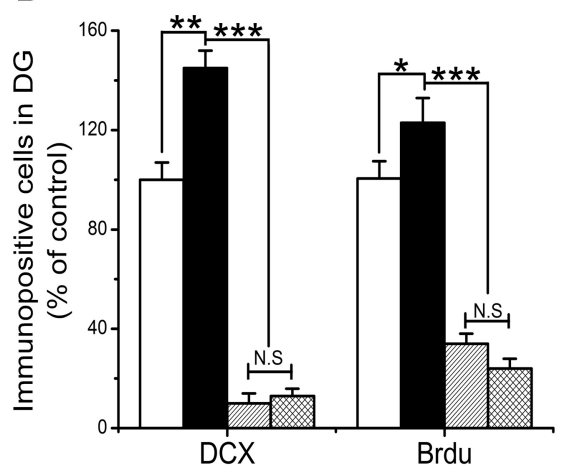

B

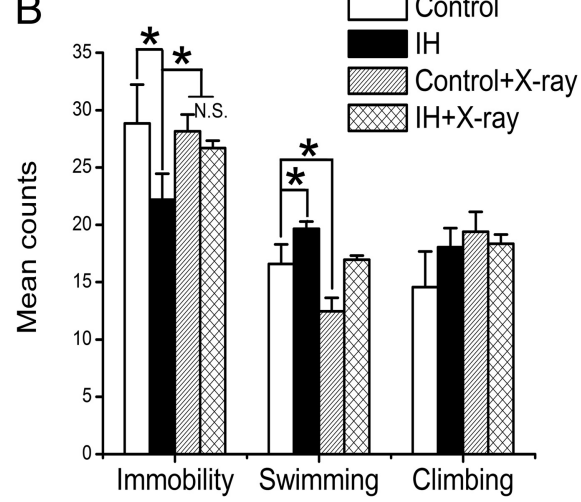

E

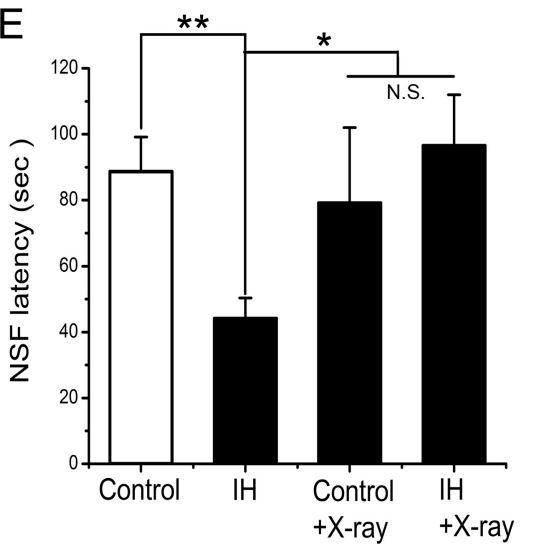

C
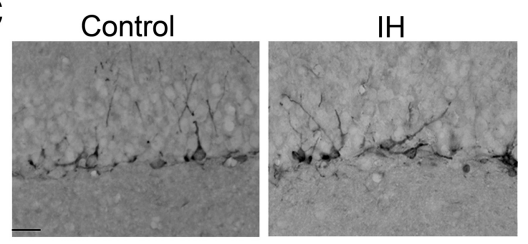

Control + X-ray
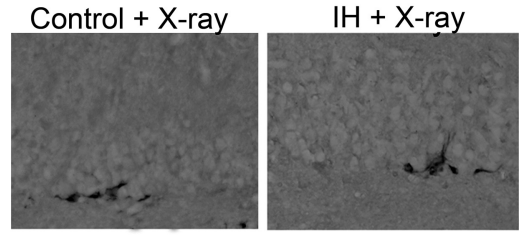

F

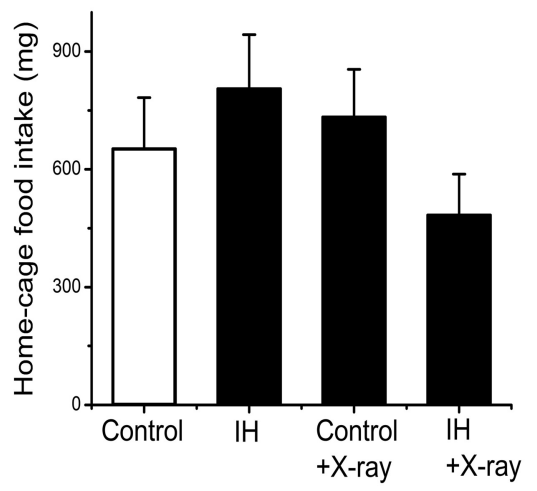

Figure 4. Hippocampal irradiation suppressed behavioral responses to IH. $A$, Experimental protocol. X-ray irradiations were given on days 1,4 , and 8 , and BrdU was injected on days 13 and 14 during IH. Behaviors (Beh.) were tested $24 \mathrm{~h}$ after IH, and rats were killed $2 \mathrm{~h}$ later. $\boldsymbol{B}$, The x-ray exposure prevented IH from reducing the immobility in the FST $(n=8)$. C, Representative images of $D C X$ immunostaining. Scale bar, $50 \mu \mathrm{m}$. D, IH significantly increased the numbers of $\mathrm{DCX}{ }^{+}$and $\mathrm{BrdU}{ }^{+}$cells in adult hippocampus $(n=8)$. These effects were blocked by the $x$-ray exposure. $\boldsymbol{E}$, The $x$-ray exposure prevented IH from reducing the latency to feed $(n=12) . F$, IH had no effect on the home-cage food consumption. ${ }^{*} p<0.05 ;{ }^{* *} p<0.01 ;{ }^{* * *} p<0.001$ versus IH by LSD post hoc test after one-way ANOVA. N.S., No significant difference. The results are expressed as means \pm SEM.

like effect of IH may involve promotion of adult hippocampal neurogenesis.

Attenuation of IH's AD-like effect by neurogenesis inhibition To determine whether adult neurogenesis is required for IH's AD-like effect, we selectively destroyed hippocampal neurogenesis by computer-guided $\mathrm{x}$-ray exposure. To this end, rats were randomly divided into four groups: control, control plus $\mathrm{x}$-ray, $\mathrm{IH}$, and $\mathrm{IH}$ plus $\mathrm{x}$-ray ( $n=8$ in each group). Behavioral tests were conducted $24 \mathrm{~h}$ after $14 \mathrm{~d} \mathrm{IH}$ (Fig. 4A). The x-ray exposure had no effect on immobility and climbing, and little effect on swimming in the FST (Fig. 4B). Most interestingly, the reduction of immobility induced by $\mathrm{IH}$ was totally blocked by the $\mathrm{x}$-ray exposure $\left(F_{(3,28)}=7.778 ; p<0.01\right.$; post hoc analysis, $p<0.05$, IH vs control; $p=0.461$, IH plus $\mathrm{x}$-ray vs control); there was no difference between control plus $\mathrm{x}$-ray and $\mathrm{IH}$ plus $\mathrm{x}$-ray groups $(p=$ 0.812 ) (Fig. $4 B$ ). To test whether $\mathrm{x}$-ray exposure is anticipated to attenuate the neurogenic effect of $\mathrm{IH}$, animals were killed $2 \mathrm{~h}$ after the FST, and brain slices were examined for BrdU and DCX (a marker for immature neurons) (Nacher et al., 2001) immunostaining (Fig. 4A). As expected, IH increased the number of $\operatorname{DCX}^{+}\left(F_{(3,28)}=144.67 ; p<0.001\right.$; post hoc analysis, $p<0.01 \mathrm{vs}$ control $)$ and $\mathrm{BrdU}^{+}\left(F_{(3,28)}=49.167 ; p<0.001\right.$; post hoc analysis, $p<0.05$ vs control) cells in the SGZ; these effects were blocked by the $\mathrm{x}$-ray exposure $(p<0.001 \mathrm{IH}$ plus $\mathrm{x}$-ray vs $\mathrm{IH})$ (Fig. $4 C, D$ ), confirming that the $\mathrm{x}$-ray irradiation suppresses hippocampal neurogenesis in adult brain (Santarelli et al., 2003; Jiang et al., 2005; Airan et al., 2007). In a parallel series, the x-ray exposure had no effect on the feeding latency in the NSF test when rats were tested $24 \mathrm{~h}$ after $\mathrm{IH}\left(F_{(3,44)}=4.918 ; p<0.01\right.$; post hoc analysis, $p=0.622$ control plus $\mathrm{x}$-ray vs control). However, the reduced latency by $\mathrm{IH}$ was also impeded by $\mathrm{x}$-ray irradiation ( $p<0.01 \mathrm{IH}$ vs control; $p=0.629 \mathrm{IH}$ plus $\mathrm{x}$-ray vs control) (Fig. $4 E)$. There was no difference in the home-cage food consumption among four groups $\left(F_{(3,44)}=0.304 ; p=0.882\right)$ (Fig. $\left.4 F\right)$. These results suggest that neurogenesis is necessary for $\mathrm{IH}$ induced AD-like effect.

To further test whether the AD-like effect of IH in depressed animals is neurogenesis dependent, rats were randomly divided into four groups (control, control plus x-ray, $\mathrm{IH}$, and $\mathrm{IH}$ plus $\mathrm{x}$-ray; $n=10$ in each group) and all of them were subjected to CMS (Fig. 5A). X-ray irradiation had no effect on rats' sensitivity to stress, as rats showed coat score deterioration after CMS (factor $\left.F_{(3,26)}=112 ; p<0.001\right)$, and there was no difference in the coat score assay between control and control plus $\mathrm{x}$-ray groups (group $F_{(3,26)}=15.077 ; p<0.001 ;$ post hoc analysis, $p=0.185$, repeated measures) (Fig. $5 B$ ), in agreement with a previous report (Surget et al. 2008). However, IH improved the coat state of the rats exhibiting depressive-like behavior $(p<0.001$ vs control); this effect was blocked by $\mathrm{x}$-ray irradiation $(p=0.817 \mathrm{IH}$ plus $\mathrm{x}$-ray vs control) (Fig. 5B). Seven days after the CMS paradigm, rats were further tested in the NSF test. Strikingly, the CMSelevated latency was decreased by $\mathrm{IH}\left(F_{(3,26)}=14.251 ; p<0.01\right.$; post hoc analysis, $p<0.01$ vs control), and this effect was also impaired by $\mathrm{x}$-ray exposure ( $p=0.629 \mathrm{IH}$ plus $\mathrm{x}$-ray vs control) (Fig. $5 C$ ). There was no different in the home-cage food con- 
A
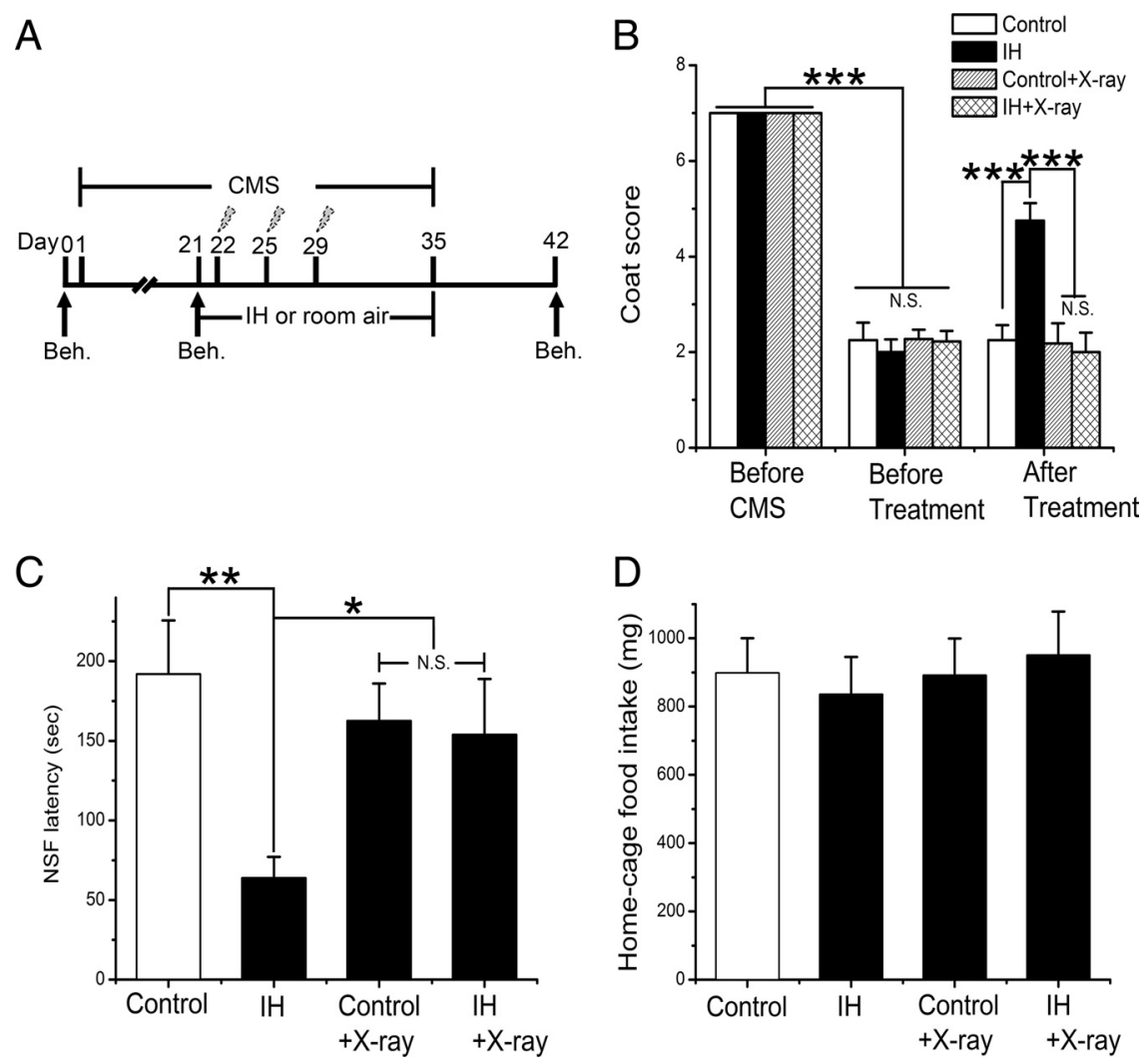

Figure 5. The AD-like effect of IH was blocked by hippocampal x-ray irradiation after CMS. $\boldsymbol{A}$, Experimental paradigm. Rats were subjected to CMS in total for 5 weeks and the coat state was assessed (Beh.). IH started at the beginning of the fourth week and lasted 2 weeks; half of the animals had their hippocampus irradiated. The NSF test was conducted $7 \mathrm{~d}$ after CMS ( $n=10$ in each group). $\boldsymbol{B}$, IH significantly improved the coat state in the rats exhibiting depressive-like behavior, which was totally blocked by $\mathrm{x}$-ray irradiation. ${ }^{* * *} p<0.001$ versus $\mathrm{IH}$ (repeated measures). C, Hippocampal $\mathrm{x}$-ray irradiation blocked IH, decreasing the elevated latency to feed induced by CMS in the NSF test. $\boldsymbol{D}$, IH had no effect on the home-cage food consumption after the NSF test. ${ }^{*} p<0.05 ;{ }^{* *} p<0.01$ versus IH by LSD post hoc analysis after one-way ANOVA. N.S., No significant difference. The results are expressed as means \pm SEM.

sumption among four groups $\left(F_{(3,26)}=0.159 ; p=0.923\right.$ ) (Fig. $5 D)$. These results in line demonstrate that promotion of neurogenesis in adult hippocampus is necessary for IH-induced ADlike effects.

BDNF is involved in the neurogenic and AD-like effects of IH To investigate the possible mechanisms underlying $\mathrm{IH}$-induced neurogenic and $\mathrm{AD}$ effects, we first examined expression of hypoxia-responsive genes and transcription factors. HIF- $1 \alpha$ and its target genes are pivotal elements of one of the main cellular responses to hypoxia that operates in numerous cell types (Sharp and Bernaudin, 2004); Among the HIF- $1 \alpha$ target genes, EPO has been shown to have an AD effect in both rat and human (Girgenti et al., 2009; Miskowiak et al., 2009). BDNF is a neurotrophic factor that has been implicated in adult neurogenesis and $\mathrm{AD}$ effects of current ADs (Newton and Duman, 2004). Recent studies have also shown that intermittent hypoxia increases BDNF in ventral spinal segments (Baker-Herman et al., 2004). Therefore, in the present study, we assessed the expressions of HIF- $1 \alpha$, EPO, and BDNF in adult hippocampus. To this end, rats subjected to IH were killed on the 7th and 14th days of hypoxia, and $7 \mathrm{~d}$ after IH (21st day; $n=4$ in each group) (Fig. 6Aa), and hippocampi were rapidly removed for Western blot analysis. HIF- $1 \alpha$ rapidly increased at the seventh day during $\mathrm{IH}\left(F_{(5,18)}=19.575 ; p<\right.$ 0.001 ; post hoc analysis, $p<0.001$ vs control); however, it returned to the level of control at $7 \mathrm{~d}$ after $\mathrm{IH}$ ( $p=0.898$ vs control)
(Fig. 6B). These results were in general agreement with a previous report (Chavez et al., 2000). EPO showed a delayed expression pattern after $\mathrm{IH}$ training as it reached the highest level (30\% increase) on the 14th day during $\mathrm{IH}\left(F_{(5,18)}=13.31\right.$; $p<0.001$; post hoc analysis, $p<0.001$ vs control) (Fig. 6C); strikingly, BDNF was increased three times that of control, and the high levels remained elevated at all time points examined $\left(F_{(5,18)}=22.787 ; p<0.01\right.$; post hoc analysis, $p<0.001$ vs control) (Fig. $6 D)$, suggesting that the neurogenic and $A D$ effects of IH may involve BDNF signaling.

To further determine whether BDNF is necessary for IH's AD-like effect, we infused K252a, a potent pharmacological inhibitor of the BDNF receptor TrkB, into the lateral ventricles of adult rats, followed by examination of behavioral changes and levels of neurogenesis (Fig. 6Ab). Infusion of solvent (ACSF/50\% DMSO) had no detectable effect on $\mathrm{IH}$ reducing the immobility in the FST $\left(F_{(2,21)}=22.761 ; p<\right.$ 0.001 ; post hoc analysis, $p<0.001 \mathrm{IH}$ plus DMSO vs control) and promoting neurogenesis $\left(F_{(2,21)}=14.27 ; p<0.001\right.$; post hoc analysis, $p<0.01 \mathrm{IH}$ plus DMSO vs control). In contrast, K252a dramatically prevented $\mathrm{IH}$ from shortening immobility ( $p=0.58$ vs control) and increased the duration of swimming $\left(F_{(2,21)}=12.188\right.$; $p<0.01$; post hoc analysis, $p=0.575$ vs control) (Fig. 6E). Moreover, the increased number of BrdU ${ }^{+}$cells in DG induced by IH was also blocked by the infusion of K252a ( $p=0.627$ vs control) (Fig. 6 F). In a parallel series, we compared the effects of infusions of anti-BDNF antibodies versus normal chicken IgY, a control Ig, on $\mathrm{IH}$-induced behavioral and neurogenic changes. To detect behavioral changes, in this experiment, we used the NSF test. IgY had no noticeable effect on IH shortening the latency to feed in the NSF test $\left(F_{(2,23)}=6.381 ; p<0.01\right.$; post hoc analysis, $p<0.01$ IH plus IgY vs control), which was blocked by anti-BDNF infusion ( $p=0.69$ vs control) (Figs. $4 E, 6 G$ ). There were no significant differences in food consumption among groups $\left(F_{(2,23)}=\right.$ 1.325; $p=0.285)$. Also, the increased number of $\mathrm{BrdU}^{+}$cells induced by $\mathrm{IH}\left(F_{(2,23)}=3.608 ; p<0.01\right.$; post hoc analysis, $p<$ $0.05 \mathrm{IH}$ plus IgY vs control) was blocked by anti-BDNF infusion $(p=0.986$ vs control) (Fig. $6 H)$. Together, these findings indicate that BDNF is necessary for the neurogenic and $\mathrm{AD}$ effects of IH.

\section{IH had no neuronal toxicity}

Hypoxia events are known to have toxic effects; therefore, it is worthwhile to investigate whether IH under our condition could cause neuronal damage in the brain. To this end, we first measured the number of $\mathrm{NeuN}^{+}$cells in the CA1, a region that is highly vulnerable to hypoxia (Lipton, 1999) and the GCL. The densities of $\mathrm{NeuN}^{+}$cells in the CA1 region and the GCL were not different between control and IH groups (data not shown). Furthermore, we performed TUNEL analysis to determine whether IH causes neuronal apoptosis; brain slices from hippocampal- 
A

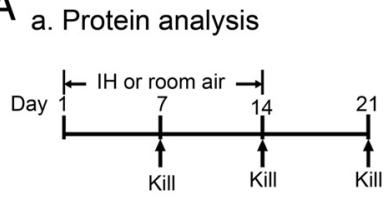

b. Intraventricular infusion

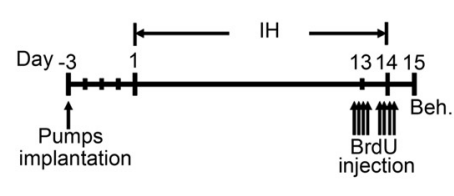

$\mathrm{E}$

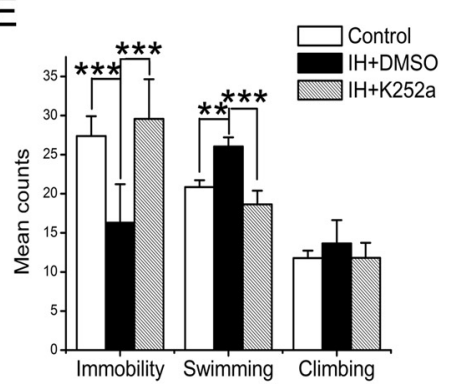

B
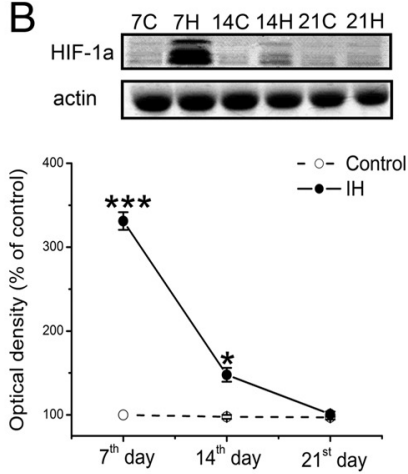

F

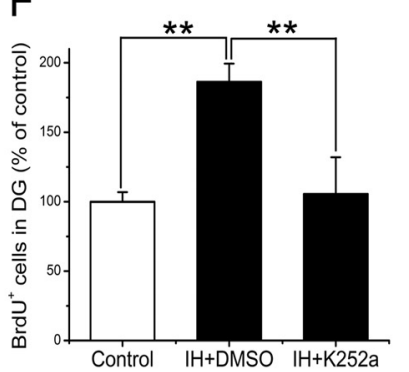

C
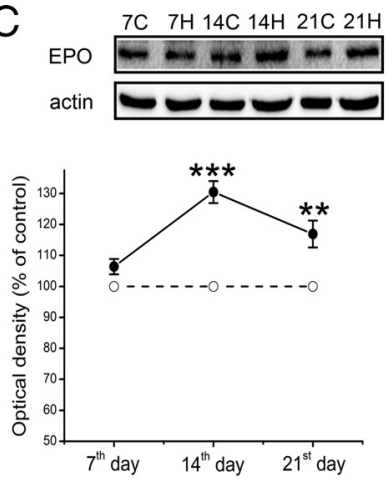

G

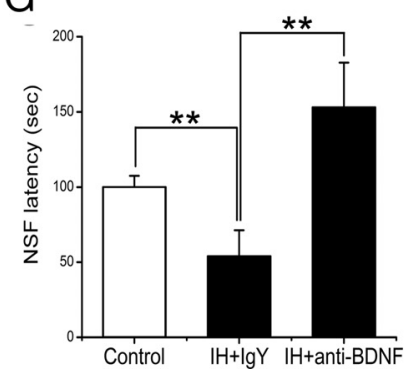

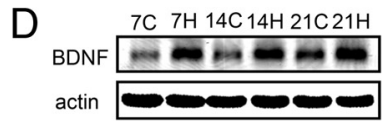

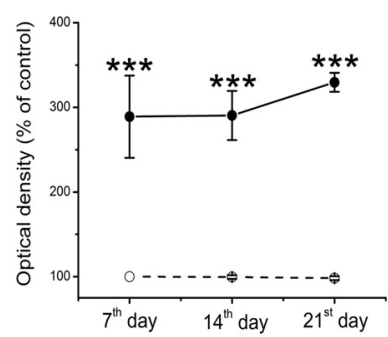

$\mathrm{H}$

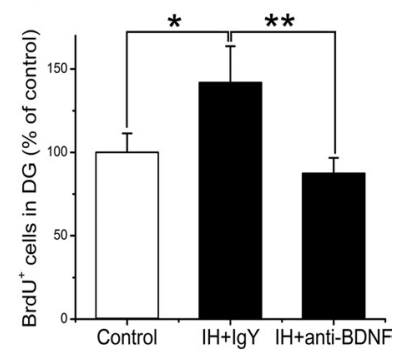

Figure 6. The neurogenic and antidepressant effects of IH involve BDNF-TrkB signaling. $A$, Experimental procedures. $\boldsymbol{a}$, Protein analysis. Rats subjected to IH were killed on days 7 and 14 during hypoxia, and $7 \mathrm{~d}$ after $\mathrm{IH}$ (day 21) $(n=4)$, and hippocampi were rapidly removed for Western blot analysis. $\boldsymbol{b}$, Intraventricular infusion paradigm. Four days after surgery, rats were subjected to $\mathrm{IH}$ training for $14 \mathrm{~d}$ and BrdU injections $(4 \times 75 \mathrm{mg} / \mathrm{kg}$, i.p.; $2 \mathrm{~h}$ interval) were given on days 13 and 14 during IH. Behavioral tests were conducted $24 \mathrm{~h}$ after IH, and rats were killed $2 \mathrm{~h}$ later. $\boldsymbol{B}-\boldsymbol{D}$, Representative Western blot images of HIF- $1 \alpha, E P 0, B D N F$, and $\beta$-actin of control $(7 C, 14 C, 21 C)$ and IH-treated $(7 \mathrm{H}, 14 \mathrm{H}, 21 \mathrm{H})$ rats. $\boldsymbol{B}, \mathbf{C}, \mathrm{HIF}-1 \alpha(\boldsymbol{B})$ rapidly increased on day 7 and returned to the level of control on day 21; EPO (C) showed a delayed expression pattern after IH. D. However, BDNF stably increased at all time points examined. $\boldsymbol{E}-\boldsymbol{H}$, Infusion of K252a blocked the AD-like effect in the FST $(\boldsymbol{E})$ and the neurogenic effect $(\boldsymbol{F})$ induced by $\mathrm{IH}(n=8)$. Similarly, anti-BDNF antibody infusion blocked the AD-like effect in the NSF test $(\boldsymbol{G})$ and the neurogenic effect $(\boldsymbol{H})$ of $\mathrm{IH}(n=9)$. Results are expressed as the mean \pm SEM. ${ }^{*} p<0.05 ;{ }^{* *} p<0.01 ;{ }^{* * *} p<0.001$ versus control or/and solvent group by LSD post hoc analysis after one-way ANOVA.

irradiated rats were used as the TUNEL-staining positive control. There was no detectable TUNEL ${ }^{+}$cells in IH-treated hippocampus, whereas $\mathrm{X}$-ray irradiated rats exhibited numerous TUNEL ${ }^{+}$ cells in the DG (data not shown), suggesting that the IH paradigm did not cause neuronal death.

\section{Discussion}

The major findings of this study are as follows. First, IH enhances neurogenesis in adult hippocampus. Second, IH produces ADlike effects in multiple animal models screening for AD activity including the CMS paradigm, the FST, and the NSF test. Third, the $\mathrm{AD}$-like effect of $\mathrm{IH}$ requires adult hippocampal neurogenesis and BDNF since it could be blocked by selective inhibitions of neurogenesis and BDNF-TrkB signaling in adult hippocampus. Together, these results identify a novel function of IH suggesting it could be developed as a potential AD therapy.

Severe hypoxic events are known to have toxic effects, whereas milder levels of oxygen desaturation may have beneficial effects (Rybnikovac et al., 2005). The actual protocol to achieve intermittent hypoxia used in experiments varies greatly in cycle length, the number of hypoxic episodes per day and days of exposure, as well as being with or without hypobaric. Compelling outcomes of intermittent hypoxia may be linked to an exact protocol type. Concerning these points, we developed a protocol for achieving $\mathrm{IH}$ in a mild manner, including a short time course of hypoxic condition ( $4 \mathrm{~h}$ a day), a long time interval $(20 \mathrm{~h})$, and lower altitudes, such as 5000 and $3000 \mathrm{~m}$. Our data showed that IH mimicking $5000 \mathrm{~m}$ in altitude enhanced the proliferation of endogenous NPCs leading to more new neurons in adult hippocampus without affecting the fate of newborn cells. Of note, IH's promotion of neurogeneis in the brain of adult rats was not because of hypoxia-induced toxicity, as all animals could endure hypoxic conditions used in this work without evidence of tissue damage.

Given the findings that chronic $\mathrm{AD}$ treatments produced $\mathrm{AD}$ effects likely achieved by promoting hippocampal neurogenesis (Santarelli et al., 2003), we hypothesized that IH-induced newborn neurons in adult hippocampus may correlate with an $\mathrm{AD}$ effect. Our subsequent experiments supported this hypothesis. We used three behavioral screens for AD activity, including the FST, CMS, and the NSF test, to investigate whether IH produces $\mathrm{AD}$ effects. Although the FST works in subacute conditions (30 min after drug injection), it does remain highly reliable in predicting the therapeutic potential of the tested compounds (Cryan et al., 2005; Dulawa and Hen, 2005). In the present study, we used fluoxetine and imipramine, two well-characterized ADs, as positive controls, and haloperidol, a typical antipsychotic, as a negative control. Both fluoxetine and imipramine produced AD-like effects in rats, whereas haloperidol had no effect. Interestingly, although acute IH ( $1 \mathrm{~d}$ for IH training) had no AD-like effect in the FST (data not shown), both $\mathrm{CoCl}_{2}$ and $14 \mathrm{~d} \mathrm{IH}$ training could produce $\mathrm{AD}$-like effects evidenced by significantly shortening the immobility. Furthermore, IH had no effect on spontaneous locomotor activity, suggesting that $\mathrm{IH}$ could be AD. Whereas $\mathrm{CoCl}_{2}$ increased the duration of climbing, $\mathrm{IH}$ shifted to increase the swimming time; although $\mathrm{CoCl}_{2}$ mimics hypoxia at the molecular level, it is possible the two are working through slightly different mechanisms. For example, exposure to hypoxia markedly increases nuclear factor- $\kappa \mathrm{B}$ DNA binding activity, whereas $\mathrm{CoCl}_{2}$ could not (Kalpana et al. 2008). The CMS paradigm in Wistar rats has been established previously as a valid model of depression 
(Willner et al., 1992). Here, we confirm that chronically stressed animals exhibit a marked degradation of the physical state of the coat. This effect can be tentatively explained by a decrease in the animal's grooming in favor of coping behaviors, which are vital in a particularly stressful situation. Also, coat state assay has been shown to be a good index of the response of rats to CMS (Griebel et al., 2002; Alonso et al., 2004), as this measure is rapidly observed and reproducible. In the present study, fluoxetine, which significantly improved the physical state of the coat of stressed animals, provides an excellent control. Most importantly, like fluoxetine, IH prevented the degradation of the state of the fur induced by CMS. The NSF test, a hyponeophagia-based paradigm that provides an anxiety-related measure that is sensitive to the effects of chronic AD treatments, also exhibits considerable potential as an animal model for studying the neurobiology of the AD response (Dulawa and Hen, 2005). Using the NSF test, we found that CMS exposure significantly elevated the hyperanxious state, which can be reversed by both fluoxetine and IH. Together, these results suggest that $\mathrm{IH}$ could have AD-like effects.

Our data also provide evidence for the neurogenesis hypothesis of the ADs' action. First, IH mimicking altitude of $5000 \mathrm{~m}$, but not $3000 \mathrm{~m}$, could promote neurogenesis in adult hippocampus, and thus produce AD-like effects. Second, CMS exposure significantly decreased the number of $\mathrm{BrdU}^{+}$cells in the DG in rats exhibiting depressive-like behavior, in agreement with a previous report (Santarelli et al., 2003). Fluoxetine and IH were able to reverse the deterioration of cell proliferation, correlated to their AD effects. Third, hippocampal x-ray irradiation blocked both the neurogenic and AD-like effects of IH in the FST and in the CMS paradigm. Because a 15 Gy dose of $\mathrm{x}$-ray was not found to alter the morphology and function of mature neurons in the hippocampus, hypothalamus, and amygdala (Santarelli et al., 2003), our data suggest that $\mathrm{IH}$, similar to fluoxetine, reduced depressive-like behavior, likely via promoting hippocampal neurogenesis (Airan RD et al., 2007; Santarelli et al., 2003).

The regulation of the expression of a wide variety of genes involved in hypoxic adaptations is largely the result of activation of HIF- $1 \alpha$. Here, the expression of HIF- $1 \alpha$ was markedly increased by $\mathrm{IH}$ in adult hippocampus, supporting the efficacy of hypoxia used in the present study. BDNF and its receptor, TrkB, are widely expressed in adult brain ( $\mathrm{Lu}, 2003)$; there is strong evidence that BDNF-TrkB signaling is involved in the mechanism of action of ADs (for review, see Duman and Monteggia, 2006; Martinowich et al., 2007; Castrén and Rantamaki, 2010). In 1995 , it was originally found that ADs increase the synthesis of BDNF (Nibuya et al., 1995). Later, several animal studies demonstrated that stress, an important factor in the etiology of depression, can decrease hippocampal BDNF levels (Smith et al., 1995; Nibuya et al., 1999; Rasmusson et al., 2002); conversely, chronic AD treatments could enhance BDNF expression in hippocampus (Larsen et al., 2008; Sillaber et al., 2008). Furthermore, infusion of BDNF into the midbrain or hippocampus induced AD-like effects in two separate depression models (Siuciak et al., 1997; Shirayama et al., 2002). Other methods have also demonstrated the involvement of BDNF-TrkB signaling in the action of ADs. Mice overexpressing TrkB appear to be more resistant to showing depressive-like behavior in stressful situations (Koponen et al., 2005). Additionally, evidence has been gathered that would suggest that BDNF-TrkB signaling is necessary for AD effects of fluoxetine and other common ADs, both with dominant negative TrkB mice and with transgenic $\mathrm{BDNF}_{\mathrm{Met}}$ (a single-nucleotide polymorphism in the BDNF gene) mice (Saarelainen et al., 2003; Chen et al., 2006). Female mice with conditional knock-out of
BDNF exhibit depression-related behaviors as well (Monteggia et al., 2007). All of these would predicate that agents promoting BDNF function might be clinical effective ADs. In the present study, we observed marked elevation of BDNF in IH-treated hippocampus. Moreover, biological and pharmacological inhibitions of BDNF-TrkB signaling blocked the neurogenic and ADlike effects of IH, suggesting IH's AD-like effect may involve BDNF-TrkB signaling. EPO is one of the well-known targets of hypoxia and is known to increase BDNF in brain (Girgenti et al., 2009). Here the IH-induced BDNF elevation is unlikely attributable to EPO, at least in the initial phase, because EPO levels in the hippocampus were not increased until day 14 ; in contrast, BDNF increase occurred on day 7 during IH. However, we cannot exclude that EPO is involved in the AD-like effects of IH. It is important to note that increased BDNF after IH may result from direct actions of hypoxia on the CNS, or indirectly from synaptic activity associated with increased respiratory drive during hypoxia (Baker-Herman et al., 2004). In addition, although BDNF was elevated by $\mathrm{IH}$, we did not detect any effect of IH on the survival and differentiation of newborn cells in SGZ. Many studies have examined the effects that BDNF-TrkB signaling has on neurogenesis in adult brain. Although few claim that manipulations of BDNF-TrkB signaling alter the differentiation of NPCs (Bath et al., 2008), many do show that this signaling is important for the survival of NPCs (Sairanen et al., 2005; Bath et al., 2008; Bergami et al., 2008; Li et al., 2008). The discrepancy between previous reports and our results can be explained by IH inducing other unknown factors that may lead to the added effects that we observed. We therefore feel it will be important to conduct additional studies to further identify the molecular and cellular adaptations that underlie the $\mathrm{AD}$ effect of $\mathrm{IH}$. In summary, the present series of experiments demonstrate that $\mathrm{IH}$ markedly produces $\mathrm{AD}$ effects via enhancing hippocampal neurogenesis and BDNFTrkB signaling in adult rats. This offers the provocative suggestion that deeply understanding the molecular and cellular mechanisms underlying physiological responses to IH could provide novel targets for the treatment of depressive disorders.

\section{References}

Airan RD, Meltzer LA, Roy M, Gong Y, Chen H, Deisseroth K (2007) Highspeed imaging reveals neurophysiological links to behavior in an animal model of depression. Science 317:819-823.

Alonso R, Griebel G, Pavone G, Stemmelin J, Le Fur G, Soubrié P (2004) Blockade of CRF (1) or V (1b) receptors reverses stress-induced suppression of neurogenesis in a mouse model of depression. Mol Psychiatry 9:278-286.

Baker-Herman TL, Fuller DD, Bavis RW, Zabka AG, Golder FJ, Doperalski NJ, Johnson RA, Watters JJ, Mitchell GS (2004) BDNF is necessary and sufficient for spinal respiratory plasticity following intermittent hypoxia. Nat Neurosci 7:48-55.

Bath KG, Mandairon N, Jing D, Rajagopal R, Kapoor R, Chen ZY, Khan T, Proenca CC, Kraemer R, Cleland TA, Hempstead BL, Chao MV, Lee FS (2008) Variant brain-derived neurotrophic factor ( $\mathrm{Val}^{66 \mathrm{Met}}$ ) alters adult olfactory bulb neurogenesis and spontaneous olfactory discrimination. J Neurosci 28:2383-2393.

Bergami M, Rimondini R, Santi S, Blum R, Gotz M, Canossa M (2008) Deletion of TrkB in progenitors alters new born neuron integration into hippocampal circuits and increases anxiety-like behavior. Proc Natl Acad Sci U S A 105:15570-15575.

Bessa JM, Ferreira D, Melo I, Marques F, Cerqueira JJ, Palha JA, Almeida OF, Sousa N (2009) The mood-improving actions of antidepressants do not depend on neurogenesis but are associated with neuronal remodeling. Mol Psychiatry 14:764-773.

Bodnoff SR, Suranyi-Cadotte B, Aitken DH, Quirion R, Meaney MJ (1988) The effects of chronic antidepressant treatment in an animal model of anxiety. Psychopharmacology 95:298-302.

Boyes BE, Kim SU, Lee V, Sung SC (1986) Immunohistochemical co- 
localization of S-100b and the glial fibrillary acidic protein in rat brain. Neuroscience 17:857-865.

Castrén E, Rantamäki T (2010) The role of BDNF and its receptors in depression and antidepressant drug action: Reactivation of developmental plasticity. Dev Neurobiol 70:289-297.

Chavez JC, Agani F, Pichiule P, LaManna JC (2000) Expression of hypoxiainducible factor-1alpha in the brain of rats during chronic hypoxia. J Appl Physiol 89:1937-1942.

Chen J, Zhang C, Jiang H, Li Y, Zhang L, Robin A, Katakowski M, Lu M, Chopp M (2005) Atorvastatin induction of VEGF and BDNF promotes brain plasticity after stroke in mice. J Cereb Blood Flow Metab 25:281-290.

Chen ZY, Jing D, Bath KG, Ieraci A, Khan T, Siao CJ, Herrera DG, Toth M, Yang C, McEwen BS, Hempstead BL, Lee FS (2006) Genetic variant $\mathrm{BDNF}\left(\mathrm{Val}^{66 \mathrm{Met}}\right)$ polymorphism alters anxiety-related behavior. Science 314:140-143.

Cryan JF, Valentinob RJ, Lucki I (2005) Assessing substrates underlying the behavioral effects of antidepressants using the modified rat forced swimming test. Neurosci Biobehav Rev 29:547-569.

Czeh B, Michaelis T, Watanabe T, Frahm J, de Biurrun G, van Kampen M, Bartolomucci A, Fuchs E (2001) Stress-induced changes in cerebral metabolites, hippocampal volume, and cell proliferation are prevented by antidepressant treatment with tianeptine. Proc Natl Acad Sci U S A 98:12796-12801.

Detke MJ, Rickels M, Lucki I (1995) Active behaviors in the rat forced swimming test differentially produced by serotonergic and noradrenergic antidepressants. Psychopharmacology 121:66-72.

Dulawa SC, Hen R (2005) Recent advances in animal models of chronic antidepressant effects: the novelty-induced hypophagia test. Neurosci Biobehav Rev 29:771-783.

Duman RS, Monteggia LM (2006) A neurotrophic model for stress-related mood disorders. Biol Psychiatry 59:1116-1127.

Garcia LS, Comim CM, Valvassori SS, Réus GZ, Barbosa LM, Andreazza AC, Stertz L, Fries GR, Gavioli EC, Kapczinski F, Quevedo J (2008) Acute administration of ketamine induces antidepressant-like effects in the forced swimming test and increases BDNF levels in the rat hippocampus. Prog Neuropsychopharmacol Biol Psychiatry 32:140-144.

Girgenti MJ, Hunsberger J, Duman CH, Sathyanesan M, Terwilliger R, Newton SS (2009) Erythropoietin induction by electroconvulsive seizure, gene regulation, and antidepressant-like behavioral effects. Biol Psychiatry 66:267-274.

Gould E, McEwen BS, Tanapat P, Galea LA, Fuchs E (1997) Neurogenesis in the dentate gyrus of the adult tree shrew is regulated by psychosocial stress and NMDA receptor activation. J Neurosci 17:2492-2498.

Gould E, Tanapat P, McEwen BS, Flugge G, Fuchs E (1998) Proliferation of granule cell precursors in the dentate gyrus of adult monkeys is diminished by stress. Proc Natl Acad Sci U S A 95:3168-3171.

Griebel G, Simiand J, Serradeil-Le Gal C, Wagnon J, Pascal M, Scatton B, Maffrand JP, Soubrie P (2002) Anxiolytic- and antidepressant-like effects of the non-peptide vasopressin V1b receptor antagonist, SSR149415, suggest an innovative approach for the treatment of stress-related disorders. Proc Natl Acad Sci U S A 99:6370-6375.

Hattori S, Hashimoto R, Miyakawa T, Yamanaka H, Maeno H, Wada K, Kunugi H (2007) Enriched environments influence depression-related behavior in adult mice and the survival of newborn cells in their hippocampi. Behav Brain Res 180:69-76.

Hunsberger JG, Newton SS, Bennett AH, Duman CH, Russell DS, Salton SR, Duman RS (2007) Antidepressant actions of the exercise-regulated gene VGF. Nat Med 13:1476-1482.

Jiang W, Zhang Y, Xiao L, Van Cleemput J, Ji SP, Bai G, Zhang X (2005) Cannabinoids promote embryonic and adult hippocampus neurogenesis and produce anxiolytic- and antidepressant-like effects. J Clin Invest 115:3104-3116.

Jin K, Mao XO, Sun Y, Xie L, Greenberg DA (2002) Stem cell factor stimulates neurogenesis in vitro and in vivo. J Clin Invest 110:311-319.

Kalpana S, Dhananjay S, Anju B, Lilly G, Sai Ram M (2008) Cobalt chloride attenuates hypobaric hypoxia induced vascular leakage in rat brain: molecular mechanisms of action of cobalt chloride. Toxicol Appl Pharmacol 231:354-363.

Kempermann G, Kuhn HG, Gage FH (1997) More hippocampal neurons in adult mice living in an enriched environment. Nature 386:493-495.

Kempermann G, Gast D, Kronenberg G, Yamaguchi M, Gage FH (2003)
Early determination and long-term persistence of adult-generated new neurons in the hippocampus of mice. Development 130:391-399.

Koponen E, Rantamäki T, Voikar V, Saarelainen T, MacDonald E, Castrén E (2005) Enhanced BDNF signaling is associated with an antidepressantlike behavioral response and changes in brain monoamines. Cell Mol Neurobiol 25:973-980.

Larsen MH, Hay-Schmidt A, Rønn LC, Mikkelsen JD (2008) Temporal expression of brain-derived neurotrophic factor (BDNF) mRNA in the rat hippocampus after treatment with selective and mixed monoaminergic antidepressants. Eur J Pharmacol 578:114-122.

Li Y, Luikart BW, Birnbaum S, Chen J, Kwon CH, Kernie SG, Bassel-Dubby R, Parada LF (2008) TrkB regulates hippocampal neurogensis and governs sensitivity to antidepressant treatment. Neuron 59:399-412.

Lin AM, Chen CF, Ho LT (2002) Neuroprotective effect of intermittent hypoxia on iron-induced oxidative injury in rat brain. Exp Neurol 176:328-335.

Lipton P (1999) Ischemic cell death in brain neurons. Phyiol Rev 79: $1432-1568$.

Liu W, Guo M, Xu YB, Li D, Zhou ZN, Wu YL, Chen Z, Kogan SC, Chen GQ (2006) Induction of tumor arrest and differentiation with prolonged survival by intermittent hypoxia in a mouse model of acute myeloid leukemia. Blood 107:698-707.

Lu B (2003) BDNF and activity-dependent synaptic modulation. Learn Mem 10:86-98.

Madsen TM, Treschow A, Bengzon J, Bolwig TG, Lindvall O, Tingström A (2000) Increased neurogenesis in a model of electroconvulsive therapy. Biol Psychiatry 47:1043-1049.

Malberg JE, Duman RS (2003) Cell proliferation in adult hippocampus is decreased by inescapable stress: reversal by fluoxetine treatment. Neuropsychopharmacology 28:1562-1571.

Malberg JE, Eisch AJ, Nestler EJ, Duman RS (2000) Chronic antidepressant treatment increases neurogenesis in adult rat hippocampus. J Neurosci 20:9104-9110.

Martinowich K, Manji H, Lu B (2007) New insights into BDNF function in depression and anxiety. Nat Neurosci 10:1089-1093.

Miskowiak KW, Favaron E, Hafizi S, Inkster B, Goodwin GM, Cowen PJ, Harmer CJ (2009) Effects of erythropoietin on emotional processing biases in patients with major depression: an exploratory fMRI study. Psychopharmacology (Berl) 207:133-142.

Monteggia LM, Luikart B, Barrot M, Theobold D, Malkovska I, Nef S, Parada LF, Nestler EJ (2007) Brain-derived neurotrophic factor conditional knockouts show gender differences in depression-related behaviors. Biol Psychiatry 61:187-197.

Mullen R, Buck CR, Smith AM (1992) NeuN, a neuronal specific nuclear protein in vertebrates. Development 116:201-211.

Nacher J, Crespo C, McEwen BS (2001) Doublecortin expression in the adult rat telencephalon. Eur J Neurosci 14:629-644.

Nemeroff C, Owens M (2002) Treatment of mood disorders. Nat Neurosci 5:1068-1070.

Newton SS, Duman RS (2004) Regulation of neurogenesis and angiogenesis in depression. Curr Neurovasc Res 1:261-267.

Ngwenya LB, Peters A, Rosene DL (2006) Maturational sequence of newly generated neurons in the dentate gyrus of the young adult rhesus monkey. J Comp Neurol 498:204-216.

Nibuya M, Morinobu S, Duman RS (1995) Regulation of BDNF and trkB mRNA in rat brain by chronic electroconvulsive seizure and antidepressant drug treatments. J Neurosci 15:7539-7547.

Nibuya M, Takahashi M, Russell DS, Duman RS (1999) Repeated stress increases catalytic TrkB mRNA in rat hippocampus. Neurosci Lett 267:81-84.

Rasmusson AM, Shi L, Duman R (2002) Downregulation of BDNF mRNA in the hippocampal dentate gyrus after re-exposure to cues previously associated with footshock. Neuropsychopharmacology 27:133-142.

Rybnikovac E, Vataeva L, Tyulkova E, Gluschenko T, Otellin V, Pelto-Huikko M, Samoilov MO (2005) Mild hypoxia preconditioning prevents impairment of passive avoidance learning and suppression of brain NGFI-A expression induced by severe hypoxia. Behav Brain Res 160:107-114.

Saarelainen T, Hendolin P, Lucas G., Koponen E, Sairanen M, MacDonald E, Agerman K, Haapasalo A, Nawa H, Aloyz R., Ernfors R, Castrén E (2003) Activation of the TrkB neurotrophin receptor is induced by antidepressant drugs and is required for antidepressant-induced behavioral effects. J Neurosci 23:349-357. 
Sahay A, Hen R (2007) Adult hippocampal neurogenesis in depression. Nat Neurosci 10:1110-1115.

Sairanen M, Lucas G, Ernfors P, Castrén M, Castrén E (2005) Brain-derived neurotrophic factor and antidepressant drugs have different but coordinated effects on neuronal turnover, proliferation, and survival in the adult dentate gyrus. J Neurosci 25:1089-1094.

Santarelli L, Saxe M, Gross C, Surget A, Battaglia F, Dulawa S, Weisstaub N, Lee J, Duman R, Arancio O, Belzung C, Hen R (2003) Requirement of hippocampal neurogenesis for the behavioral effects of antidepressants. Science 301:805-809.

Serebrovskaya TV, Manukhina EB, Smith ML, Downey HF, Mallet RT (2008) Intermittent hypoxia: cause of or therapy for systemic hypertension? Exp Biol Med (Maywood) 233:627-650.

Sharp FR, Bernaudin M (2004) HIF1 and oxygen sensing in the brain. Nat Rev Neurosci 5:437-448.

Shingo T, Sorokan ST, Shimazaki T, Weiss S (2001) Erythropoietin regulates the in vitro and in vivo production of neuronal progenitors by mammalian forebrain neural stem cells. J Neurosci 21:9733-9743.

Shirayama Y, Chen AC, Nakagawa S, Russell DS, Duman RS (2002) Brainderived neurotrophic factor produces antidepressant effects in behavioral models of depression. J Neurosci 22:3251-3261.

Sillaber I, Panhuysen M, Henniger MS, Ohl F, Kühne C, Pütz B, Pohl T, Deussing JM, Paez-Pereda M, Holsboer F (2008) Profiling of behavioral changes and hippocampal gene expression in mice chronically treated with the SSRI paroxetine. Psychopharmacology (Berl) 200:557-572.

Siuciak JA, Lewis DR, Wiegand SJ, Lindsay RM (1997) Antidepressant-like effect of brain-derived neurotrophic factor (BDNF). Pharmacol Biochem Behav 56:131-137.

Smith MA, Makino S, Kvetnansky R, Post RM (1995) Stress and glucocorticoids affect the expression of brain-derived neurotrophic factor and neurotrophin-3 mRNAs in the hippocampus. J Neurosci 15:1768-1777.
Surget A, Saxe M, Leman S, Ibarguen-Vargas Y, Chalon S, Griebel G, Hen R, Belzung C (2008) Drug-dependent requirement of hippocampal neurogenesis in a model of depression and of antidepressant reversal. Biol Psychiatry 64:293-301.

van Praag H, Kempermann G, Gage FH (1999) Running increases cell proliferation and neurogenesis in the adult mouse dentate gyrus. Nat Neurosci 2:266-270.

Willner P, Muscat R, Papp M (1992) Chronic mild stress-induced anhedonia: a realistic animal model of depression. Neurosci Biobehav Rev 16:525-534.

Xi L, Taher M, Yin C, Salloum F, Kukreja RC (2004) Cobalt chloride induces delayed cardiac preconditioning in mice through selective activation of HIF-1 $\alpha$ and AP-1 and iNOS signaling. Am J Physiol Heart Circ Physiol 287:H2369-H2375.

Yan HC, Qu HD, Sun LR, Li SJ, Cao X, Fang YY, Jie W, Bean JC, Wu WK, Zhu XH, Gao TM (2010) Fuzi polysaccharide-1 produces antidepressantlike effects in mice. Int J Neuropsychopharmacol 13:623-633.

Yuan Y, Hilliard G, Ferguson T, Millhorn DE (2003) Cobalt inhibits the interaction between hypoxia-inducible factor-alpha and von HippelLindau protein by direct binding to hypoxia-inducible factor-alpha. J Biol Chem 278:15911-15916.

Zhu LL, Zhao T, Li HS, Zhao H, Wu LY, Ding AS, Fan WH, Fan M (2005) Neurogenesis in the adult rat brain after intermittent hypoxia. Brain Res 1055:1-6.

Zhu WZ, Xie Y, Chen L, Yang HT, Zhou ZN (2006) Intermittent high altitude hypoxia inhibits opening of mitochondrial permeability transition pores against reperfusion injury. J Mol Cell Cardiol 40:96-106.

Zhu XH, Li SJ, Hu HH, Sun LR, Das M, Gao TM (2010) Neuroprotective effects of Xiao-Xu-Ming decoction against ischemic neuronal injury in vivo and in vitro. J Ethnopharmacol 127:38-46. 